\title{
Seleção de Extratos Vegetais para Indução de Resistência e Ativação de Respostas de Defesa em Cacaueiro contra a Vassoura-de-bruxa
}

\author{
Mário Lúcio V. Resende ${ }^{1}$, João de Cássia B. Costa ${ }^{2}$, Fábio R. Cavalcanti ${ }^{3}$ \\ Pedro M. Ribeiro Júnior ${ }^{1}$ \& Fabrício R. Camilo ${ }^{1}$
}

\begin{abstract}
${ }^{1}$ Departamento de Fitopatologia, Universidade Federal de Lavras, Cx. Postal 3037, CEP 37200-000, Lavras, MG, Brasil, e-mail: mlucio@ufla.br; ${ }^{2}$ CEPEC/CEPLAC/MAPA, Seção de Fitopatologia, Cx. Postal 07, CEP 45650-000, Itabuna, BA,

Brasil; ${ }^{3}$ Campus Professora Cinobelina Elvas, Universidade Federal do Piauí, CEP 64900-000, Bom Jesus, PI, Brasil
\end{abstract}

Autor para correspondência: Mário Lúcio V. Resende

RESENDE, M.L.V., COSTA, J.C.B., CAVALCANTI, F.R., RIBEIRO JÚNIOR, P.M. \& CAMILO, F.R. Seleção de extratos vegetais para indução de resistência e ativação de respostas de defesa em cacaueiro contra a vassoura-de-bruxa. Fitopatologia Brasileira 32:213-221. 2007.

\begin{abstract}
RESUMO
Objetivou-se encontrar novos indutores de resistência contra a vassoura-de-bruxa (Crinipellis perniciosa) do cacaueiro (Theobroma cacao), com eficácia igual ou superior a aquela conferida pelo indutor de resistência padrão, acibenzolar-S-metil, e estudar possíveis respostas de defesa ativadas no cacaueiro por esses eliciadores mais eficazes. Foram testados extratos de várias plantas, principalmente, nativas do cerrado mineiro, bem como extratos provenientes de outras espécies cultivadas. Verificou-se que extratos aquosos produzidos a partir de ramos de lobeira (Solanum lycocarpum) com sintomas de vassoura-de-bruxa induziram proteção de mudas de cacaueiros contra a mesma doença em nível estatisticamente similar à proteção conferida pelo ASM. O extrato aquoso e fervido de lobeira, aqui denominado VLA, não foi tóxico in vitro, pelo contrário, induziu maior crescimento do fungo C. perniciosa em BDA, quando comparado à testemunha (crescimento em BDA puro). Quando se quantificou a atividade de proteínas relacionadas à patogênese (quitinase e $\beta$ 1,3-glucanase) estimuladas por VLA e ASM (como padrão), observou-se que ambos os tratamentos induziram maiores atividades de peroxidase, quitinase e $\beta$-1,3-glucanase em mudas de cacaueiros, comparados às respectivas testemunhas, no período de 4 a 18 dias após a pulverização (DAP). Também o teor de lignina aumentou em plantas tratadas com VLA ou ASM, principalmente aos 18 DAP.
\end{abstract}

Palavras-chave adicionais: Resistência induzida, Theobroma cacao, Solanum lycocarpum, acibenzolar-S-metil (ASM), proteínas relacionadas à patogênese, lignina.

\begin{abstract}
Selection of plant extracts to induce resistance and activate defense responses in cocoa against witches' broom disease

The objective of this study was to find new inducers of resistance against witches' broom disease (Crinipellis perniciosa) of cocoa (Theobroma cacao), with higher or equal efficacy to that conferred by the standard inducer acibenzolarS-methyl and to study possible defense responses activated in cocoa by these more efficient elicitors. Extracts from several plants were tested, mainly those from native plants from the savannah of Minas Gerais State, as well as extracts from cultivated plants. It was verified that aqueous extracts from "lobeira" (Solanum lycocarpum) tree with symptoms of witches' broom induced protection of cocoa seedlings at similar levels as that conferred by ASM. The aqueous and boiled extract from "lobeira", here named VLA, was not toxic in vitro: in fact, it promoted $C$. perniciosa growth on PDA medium. The activities of pathogenesis-related proteins chitinase and $\beta-1,3$ - glucanase stimulated by VLA and ASM were assessed and it was verified that both treatments induced higher activities of peroxidase, chitinase and $\beta$-1,3-glucanase in cocoa seedlings, compared to the respective controls, from 4 to 18 days after spraying (DAS). The lignin content also increased in plants treated with VLA or ASM, mainly at 18 DAS.

Additional keywords: Induced resistance, Theobroma cacao, Solanum lycocarpum, acibenzolar-S-methyl (ASM), pathogenesis-related proteins, lignin.
\end{abstract}

\section{INTRODUÇÃO}

A vassoura-de-bruxa (Crinipellis perniciosa (Stahel) Singer) é a principal doença do cacaueiro (Theobroma cacao L.) no Brasil, podendo causar perdas de até $90 \%$ na produção. O país, de grande exportador de amêndoas de cacau, passou a importador, para suprir as necessidades das indústrias de moagem aqui instaladas.
O patógeno ataca principalmente os tecidos meristemáticos em crescimento, provocando sintomas característicos de desequilíbrio hormonal na interação patógeno-hospedeiro. As medidas recomendadas para o controle da vassoura-de-bruxa estão inseridas no manejo integrado da doença, adotando-se métodos de controle genético, cultural, químico e biológico (Luz et al., 1997; Costa et al., 2006). Métodos alternativos mais recentes 
incluem a busca de fungicidas naturais, principalmente à base de extratos vegetais (Bastos, 1997) e a resistência induzida (Resende et al. 2000; 2002b).

A resistência induzida (RI) pode ser ativada em plantas por uma série de substâncias, evitando ou atrasando a entrada ou a subseqüente atividade do patógeno em seus tecidos, por meio de mecanismos de defesa próprios (Athayde Sobrinho et al., 2005; Nojosa et al., 2005). Vários agentes podem induzir a produção de "sinais" no tecido vegetal, disparando reações que culminarão em proteção duradoura contra uma ampla gama de fitopatógenos. A percepção se dá quando moléculas do agente indutor se ligam a moléculas receptoras situadas, provavelmente, na membrana plasmática da célula vegetal. Essas reações desencadeiam a ativação de vários mecanismos de defesa (Resende et al., 2002 a,b). A RI pode ser dividida em duas categorias, a resistência sistêmica adquirida (SAR) e a resistência sistêmica induzida (ISR) (Van Loon et al., 1998). Na SAR, a resistência desenvolve-se de forma sistêmica em resposta a um patógeno que causa uma lesão necrótica (HR) ou por aplicação exógena de ácido salicílico ou compostos sintéticos, como o acibenzolarS-metil (ASM) e o ácido 2,6-dicloroisonicotínico (INA). Nesta, a resistência expressa, geralmente, é efetiva contra um amplo espectro de patógenos e está associada à produção de proteínas relacionadas à patogênese (PRP's). Muitas delas possuem atividade antimicrobiana e são excelentes marcadores moleculares para a resposta de resistência. Já na ISR, geralmente induzida por rizobactérias, a sinalização é mediada pelo ácido jasmônico e etileno (Van Loon et al., 1998).

Avanços nas pesquisas envolvendo RI em plantas vem sendo acompanhados pelo surgimento de novos produtos comerciais que apresentam maior eficácia, estabilidade e menor impacto ao ambiente, sendo capazes de propiciar melhora na produtividade agrícola, devido à redução de perdas ocasionadas por patógenos e, em alguns casos, incrementos no desenvolvimento vegetativo (Resende et al., 2006). O ASM foi o primeiro indutor de SAR liberado para uso comercial (Lyon \& Newton, 1997) e atualmente muitos outros produtos já estão disponíveis no mercado ou em fase de pesquisa (Resende et al., 2006).

Geralmente, a indução de resistência ocorre pela ativação de genes que codificam uma série de PRP's e enzimas envolvidas na síntese de fitoalexinas e lignina (Vidhyasekaran, 1988; Van Loon, 1997; Moraes, 1998; Resende et al., 2002a). A detecção e quantificação da expressão de genes que levam a essas substâncias, seria uma das formas de separar o efeito indutor de resistência do efeito tóxico direto de determinado produto. As PRP's englobam famílias de proteínas com características variadas (quitinases, $\beta-1,3$-glucanases, lisozimas, peroxidases, osmotinas, dentre outras), mas com o fato em comum de estarem todas relacionadas aos processos de defesa durante a patogênese, apresentando dessa forma, potencial para serem exploradas nos programas de indução de proteção em plantas (Van Loon \& Van Strien, 1999).

No presente trabalho foi investigada a eficácia da pulverização foliar de mudas de cacaueiro com vários extratos vegetais de plantas sadias e doentes, bem como de basidiomas de $C$. perniciosa na proteção contra a vassourade-bruxa, utilizando-se o indutor de resistência ASM, como padrão em todos os experimentos. Para os melhores tratamentos obtidos, foram realizados estudos de toxidez direta sobre $C$. perniciosa e análises de respostas de defesa ativadas em cacaueiro, após a aplicação desses tratamentos. Dentre as PRP's, foram focadas no presente trabalho as quitinases e as $\beta$-1,3-glucanases, por possuírem efeito direto sobre o patógeno, atuando na degradação de componentes da parede celular fúngica e as peroxidases, por estarem envolvidas na síntese de lignina, polímero fenólico cujo acúmulo nos tecidos do cacaueiro, certamente dificultaria a infecção por C. perniciosa. O conteúdo de lignina foi também quantificado em plantas tratadas com os melhores indutores de resistência encontrados, comparativamente com plantas testemunhas não tratadas.

\section{MATERIAL E MÉTODOS}

\section{Material vegetal e condições de crescimento em casa-de- vegetação}

Foram utilizadas sementes de cacau da cultivar Catongo, provenientes do Centro de Pesquisas do Cacau, CEPEC/CEPLAC/MAPA, Itabuna BA. As mudas foram devidamente cultivadas em bandejas de isopor com 72 células, contendo o substrato Plantmax Hortaliças $(\mathrm{HT})^{\circledR}$ (volume aproximado de 0,4 L.célula $^{-1}$ ) e adubadas semanalmente com solução nutritiva de Hoagland \& Arnon (1950) (50 \% da força iônica). Durante os experimentos, as mudas foram mantidas em casa-de-vegetação, com temperatura de $25 \pm 3{ }^{\circ} \mathrm{C}$ e umidade relativa do ar em torno de $80 \%$, controladas através de um sistema automatizado de nebulização, sob condições ajustáveis em casas-de-vegetação do Departamento de Fitopatologia (DFP) da UFLA.

\section{Produção de inóculo e inoculação das mudas}

O inóculo foi obtido a partir de vassouras infectadas (ramos secos) provenientes de Ilhéus, BA, coletadas no biênio 2005-06. Essas vassouras foram mantidas em câmaras indutoras da produção de basidiomas de C. perniciosa, denominada de vassoureiro, sob regime de nebulização periódica. Os basidiósporos coletados em solução de glicerol $16 \%$, conforme Frias et al. (1995), foram armazenados em nitrogênio líquido, para uso posterior.

As inoculações foram sempre realizadas sete dias após a pulverização dos tratamentos, executadas ao final da tarde, com a deposição de uma gota da suspensão de basidiósporos na concentração de $1 \times 10^{5}$ basidiósporos viáveis. $\mathrm{mL}^{-1}$ no meristema apical de cada muda com 30 dias de idade. Durante vinte e quatro horas após o processo de inoculação, a umidade relativa do ar foi mantida próxima a $100 \%$, para propiciar condições à penetração fúngica, 
mantendo-se gotículas de água livre no ápice de cada muda. A percentagem de germinação (viabilidade) dos basidiósporos foi quantificada antes e depois da inoculação, em lâminas escavadas com três cavidades. Para tal, lâminas contendo a suspensão de basidiósporos foram mantidas em câmara úmida por 24 horas. Após esse período, foram adicionados $30 \mu \mathrm{L}$ do corante azul de lactofenol em cada cavidade, e posteriormente foi determinada a percentagem de esporos germinados, sendo amostrados 200 basidiósporos por cavidade (contagem realizada na linha do diâmetro da cavidade, marcada com caneta na parte posterior da lâmina). Somente foram utilizadas na inoculação, suspensões de esporos com viabilidade superior a $80 \%$.

\section{Avaliação da doença}

Foram realizadas avaliações da incidência de vassoura-de-bruxa nas mudas aos 30,45 e 60 dias após as inoculações. A percentagem de mudas doentes foi então calculada para cada bloco. Em se tratando de avaliações acumulativas, somente dados da avaliação aos 60 dias serão aqui apresentados.

\section{Delineamento experimental e análises estatísticas}

Todos os experimentos em casa-de-vegetação foram instalados no delineamento de blocos casualizados, com quatro repetições, sendo utilizadas doze plantas por parcela, totalizando 48 plantas por tratamento. Os dados coletados foram submetidos a análises de variância e testes de médias (Teste de Tukey).

Experimento 1. Estudo da proteção induzida em cacaueiro contra a vassoura-de-bruxa, por extratos de tecidos de cafeeiro e de biomassa cítrica

Foram utilizados extratos aquosos, fervidos e a frio, de casca de frutos de café e de folhas de café infectadas com Hemileia vastatrix Berk et Br. Esses tecidos de cafeeiros são ricos em compostos eliciadores (compostos fenólicos da planta e compostos de origem fúngica no tecido infectado), e foram eficazes in vitro contra $C$. perniciosa. Formulações a base de extratos de folhas e de cascas de frutos de café foram objetos de pedidos de patentes por parte de nosso grupo de pesquisa na UFLA (INPI, Privilégio de Inovação PI 0603575-2, FORMULAÇÃO PARA INDUÇÃO DE RESISTÊNCIA. 02 de Agosto de 2006).

Também foi incluído no experimento, uma formulação a base de biomassa cítrica, rica em flavonóides, polifenóis, fitoalexinas e ácidos orgânicos (Ecolife $\left.{ }^{\circledR}\right)$, a qual vem sendo utilizada com sucesso contra doenças em bananeira, morango e videira (Quinabra, 2006).

Os extratos de tecidos do cafeeiro, procedentes de variedades suscetíveis à ferrugem, foram preparados no Laboratório de Fisiologia do Parasitismo do DFP-UFLA, na proporção de $80 \mathrm{~g}$ (massa seca) de tecido moído por litro de água destilada. O material em suspensão foi fervido em refluxo por duas horas. Após a fervura, os extratos foram filtrados a vácuo e armazenados em congelador $\left(-20^{\circ} \mathrm{C}\right)$.
Para o preparo dos extratos a frio, erlenmeyers contendo as suspensões foram agitados por quatro horas a $130 \mathrm{rpm}$ em temperatura ambiente. Após a agitação, foi também realizada a filtragem a vácuo e armazenagem em congelador $\left(-20^{\circ} \mathrm{C}\right)$. Os tratamentos utilizados no experimento foram: a) extrato aquoso de casca de café, a frio; b) extrato aquoso de casca de café, fervido; c) extrato aquoso de folha de cafeeiro com H. vastatrix, a frio; d) extrato aquoso de folha de cafeeiro com H. vastatrix, fervido; e) extrato aquoso de folha de cafeeiro sadia, a frio; f) extrato aquoso de folha de cafeeiro sadia, fervido; g) Ecolife ${ }^{\circledR}\left(5\right.$ mL.L $\left.\mathrm{L}^{-1}\right)$ (extrato de biomassa cítrica); h) ASM (0,2 g i.a... $\left.\mathrm{L}^{-1}\right)$; i) testemunha inoculada (plântulas não pulverizadas com indutor e inoculadas com C. perniciosa) e j) testemunha absoluta (plântulas não pulverizadas com indutor e não inoculadas).

Experimento 2. Estudo da proteção induzida em cacaueiro contra a vassoura-de-bruxa, por extratos provenientes de basidiomas de Crinipellis perniciosa e de vassouras-de-lobeira

Em experimentos preliminares foi evidenciado o potencial de indução de resistência em mudas de cacaueiro contra $C$. perniciosa, por basidiósporos do referido fungo provenientes de lobeira (não patogênico ao cacaueiro). Entretanto, devido a uma produção pequena de basidiósporos, decidiu-se, no presente experimento, testar-se o efeito de extratos de basidiomas como um todo e também de extratos de vassouras secas provenientes de lobeira (Solanum lycocarpum St. Hil.), abundantes no sul de Minas e no cerrado brasileiro em geral. Para comparação, foram testados extratos de ramos sadios de lobeira (sem vassourade-bruxa).

Foram utilizados extratos aquosos, fervidos ou a frio, na proporção de $80 \mathrm{~g}$ (peso seco) de tecido fúngico ou vegetal moído por litro de água destilada. O procedimento para o preparo e armazenamento dos extratos foi o mesmo descrito no item anterior, para os extratos provenientes de tecidos do cafeeiro. Utilizaram-se os seguintes tratamentos: a) extrato aquoso de vassoura-de-lobeira (S. lycocarpum), a frio; b) extrato aquoso de vassoura-de-lobeira, fervido; c) extrato aquoso de ramo sadio de lobeira, sem vassoura-debruxa, a frio; d) extrato aquoso de ramo sadio de lobeira, sem vassoura-de-bruxa, fervido; e) extrato aquoso de basidioma de C. perniciosa em lobeira, a frio; f) extrato aquoso de basidioma de C. perniciosa em lobeira, fervido); g) acibenzolar-S-metil, ASM, a 0,2 g i.a... - $^{-1}$ e h) testemunha inoculada.

Experimento 3. Caracterização dos mecanismos bioquímicos envolvidos na resposta de defesa de mudas de cacaueiros tratadas com ASM e VLA

Considerando que o VLA (extrato aquoso de vassoura-de-lobeira, fervido) havia sido o único extrato com desempenho similar ao indutor de resistência padrão ASM nos experimentos realizados anteriormente, esses dois tratamentos foram selecionados para comparação do ponto 
de vista de indução de respostas de defesa em mudas de cacau cv. Catongo, avaliando-se as atividades das enzimas peroxidase, quitinase e $\beta$-1,3-glucanases. Como testemunhas foram utilizadas plantas pulverizadas somente com água.

Os tempos de coleta das amostras para verificação das respostas de defesa foram de 4, 8, 13 e 18 dias após a aplicação dos tratamentos indutores, exceto para lignina total que foi avaliada somente 13 e 18 dias após a aplicação dos tratamentos.

\section{Preparo de extratos foliares para determinação de} proteínas totais e atividade de peroxidase

Os tecidos vegetais ( $1,5 \mathrm{~g}$ de brotações novas) foram macerados em tampão de acetato de sódio $50 \mathrm{mM}, \mathrm{pH}$ 5,2 por três minutos. Estes extratos foram utilizados para a determinação de proteínas totais, através do método de Bradford (1976), utilizando soluções de albumina sérica bovina (BSA) para fazer a calibração da curva padrão do reagente de Bradford.

A atividade de peroxidase de guaiacol (POX) foi determinada pela adição de $25 \mu \mathrm{L}$ do extrato enzimático ajustado para $2 \mathrm{~mL}$ da solução contendo acetato de sódio 50

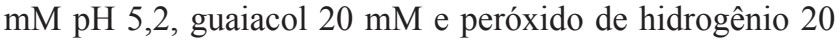
$\mathrm{mM}$. Após incubação em $30^{\circ} \mathrm{C}$ por $10 \mathrm{~min}$, a absorbância foi medida a $480 \mathrm{~nm}$. Uma unidade de POX foi expressa como variação de $1 \mathrm{OD}_{480}$ por miligrama de proteína solúvel por minuto $\left(\Delta 480 \mathrm{~nm} \cdot \mathrm{mgP}^{-1} \cdot \mathrm{min}^{-1}\right)$. Proteínas foram separadas por eletroforese em gel de poliacrilamida, em condições nativas, de acordo com Laemmli (1970), usando-se gel de separação de $12,5 \%$ sobreposto por gel de empilhamento de $5 \%$. Extratos enzimáticos foram preparados em presença de azul de bromofenol e glicerol. Um volume referente a um valor fixo de $15 \mu \mathrm{g}$ de proteína de cada amostra foi adicionado aos poços do gel de empilhamento. Para a revelação das bandas protéicas com atividade de peroxidase, o gel foi imerso em $20 \mathrm{~mL}$ de solução de diaminobenzidina (10 mg), tampão tris-HCl $2 \mathrm{M}, \mathrm{pH} \mathrm{8,3}(1 \mathrm{~mL})$, peróxido de hidrogênio $30 \%(0,02 \mathrm{~mL})$ e água Milli-Q (q.s.p. $20 \mathrm{~mL})$. Após o aparecimento das bandas, a reação foi interrompida por lavagens sucessivas com água destilada.

\section{Determinação do conteúdo de Lignina}

O conteúdo de lignina foi determinado como descrito por Stadnik (1999), por meio do ensaio com ácido tioglicólico (Monties, 1989). Tecidos de brotações novas $(0,2 \mathrm{~g})$, coletados aos 13 e 18 dias após a aplicação dos tratamentos, foram macerados em nitrogênio líquido e incubados em acetona por 24 horas para a despigmentação; em seguida, os tecidos foram centrifugados, o sobrenadante foi retirado e o restante foi seco, por 24 horas, à temperatura ambiente. Após a despigmentação, o material foi tratado com $5 \mathrm{~mL}$ de uma mistura de ácido tioglicólico e ácido

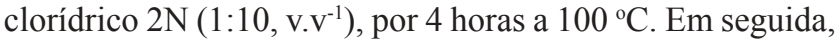
o material foi centrifugado, lavado com água e centrifugado novamente, quando foram adicionados $5 \mathrm{~mL}$ de hidróxido de sódio $0,5 \mathrm{~N}$ por 18 horas para a extração do ácido lignotioglicólico do precipitado. As amostras foram então centrifugadas, acidificadas com $200 \mu \mathrm{L}$ de ácido clorídrico concentrado e incubadas no gelo por quatro horas. Em seguida, uma nova centrifugação foi realizada, o precipitado foi ressuspendido em $\mathrm{NaOH} 0,5 \mathrm{~N}$ e a absorbância dessa solução foi determinada a $280 \mathrm{~nm}$, em espectrofotômetro. A quantidade de lignina foi calculada com base em uma curva padrão, constituída com diferentes concentrações de lignina padrão (alkali, 2-hidroxipropil éter). Os resultados foram expressos em micrograma de lignina por grama de matéria fresca $\left(\mu \mathrm{g} \cdot \mathrm{gMF}^{-1}\right)$.

\section{Determinação das atividades de quitinase e $\beta$-1,3- glucanase}

A atividade de quitinase em mudas de cacau foi determinada pela adição de $70 \mu \mathrm{L}$ do extrato enzimático ajustado para $310 \mu \mathrm{L}$ da solução contendo acetato de sódio $50 \mathrm{mM} \mathrm{pH} \mathrm{5,2} \mathrm{e} 60 \mu \mathrm{L}$ de CM-Chitin-RBV (2 mg. $\left.\mathrm{mL}^{-1}\right)$, um substrato específico para quitinase (LOEWE Biochemica $\mathrm{GmbH}$ ), em micro-placas de 96 cavidades (com volume de $350 \mu \mathrm{L}$ ). Após a incubação a $35^{\circ} \mathrm{C}$ por $80 \mathrm{~min}$, as amostras foram acidificadas com $50 \mu \mathrm{L}$ de $\mathrm{HCl} 0,5 \mathrm{~N}$, resfriadas em banho de gelo por 10 min e centrifugadas (1450 x $g$ por 10 min). Uma alíquota de $210 \mu \mathrm{L}$ do sobrenadante de cada amostra foi transferida para uma nova micro-placa para leitura a $492 \mathrm{~nm}$ em um leitor EIA-compatível.

A atividade de $\beta$-1,3-glucanase foi medida seguindo método análogo, apenas com a troca do substrato para CM-Curdlan-RBB (4 mg.mL ${ }^{-1}$; LOEWE Biochemica $\mathrm{GmbH}$ ) e com o ajuste da alíquota do extrato enzimático para $100 \mu \mathrm{L}$. Para promover a ação hidrolítica da $\beta$-1,3glucanase foi adotado um tempo de incubação de 100 min. a $35^{\circ} \mathrm{C}$. Uma alíquota de $210 \mu \mathrm{L}$ do sobrenadante de cada amostra foi transferida para uma nova micro-placa para leitura a $620 \mathrm{~nm}$.

\section{RESULTADOS E DISCUSSÃO}

\section{Experimento 1. Estudo da proteção induzida em cacaueiro contra a vassoura-de-bruxa, por extratos de tecidos de cafeeiro e de biomassa cítrica}

$\mathrm{Na}$ avaliação da incidência de vassoura-de-bruxa realizada aos 60 dias após a inoculação, observou-se que nenhum tratamento foi estatisticamente diferente da testemunha, exceto o tratamento com ASM (Figura 1A). Extratos de folhas e de casca de frutos de café têm sido eficazes contra doenças do próprio cafeeiro e também do tomateiro e do algodoeiro (INPI, Pedido de patente, Protocolo número 0000220604167501, FORMULAÇÃO PARA INDUÇÃO DE RESISTÊNCIA... 02 de Agosto de 2006).

Estudos anteriores haviam detectado a presença de eliciadores de resistência em folhas de cafeeiro infectadas pela ferrugem. Esporos de $H$. vastatrix inativados por autoclavagem e preparados em forma de filtrado aquoso induziram proteção contra $H$. vastatrix 

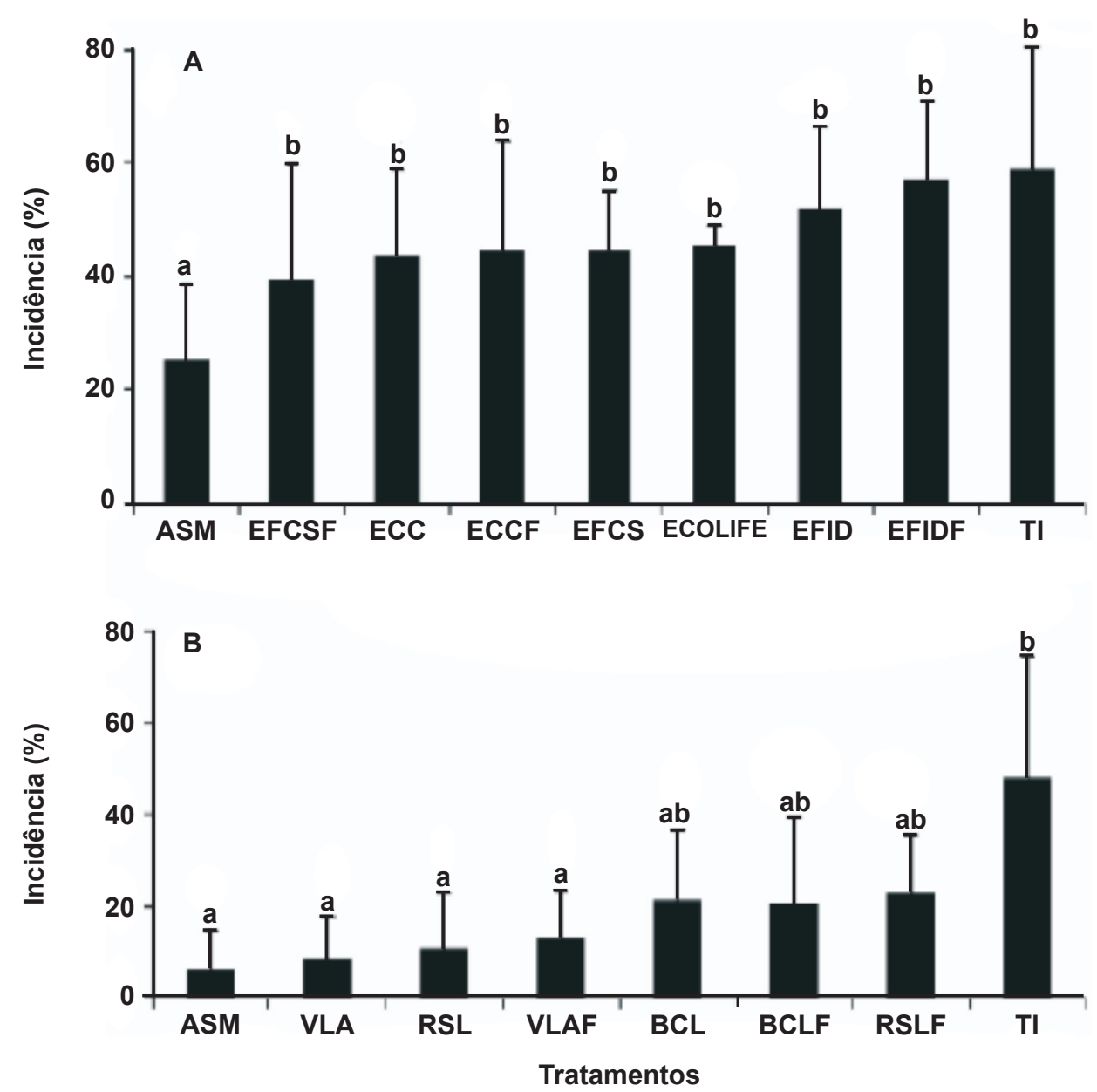

FIG. 1 - Incidência da vassoura-de-bruxa aos 60 dias após inoculação de C. perniciosa em mudas de cacaueiros tratadas em "A" com: ASM - acibenzolar-S-metil; EFCSF - extrato aquoso de folhas de cafeeiro sadias, a frio; ECC - extrato aquoso de casca de café, fervido; ECCF - extrato aquoso de casca de café, a frio; EFCS - extrato aquoso de folhas de cafeeiro sadias, fervido; ECOLIFE ${ }^{\circledR}$ - extrato de biomassa cítrica; EFID - extrato aquoso de folhas de cafeeiro com $H$. vastatrix, fervido; EFIDF - extrato aquoso de folhas de cafeeiro com $H$. vastatrix, a frio; e TI - testemunha inoculada. E em "B": ASM - acibenzolar-S-metil; VLA - extrato aquoso de vassoura-de-lobeira, fervido; RSL - extrato aquoso de ramo sadio de lobeira, fervido; VLAF - extrato aquoso de vassoura-de-lobeira, a frio; BCL - extrato aquoso de basidioma de C. perniciosa em lobeira, fervido; BCLF - extrato aquoso de basidioma de $C$. perniciosa em lobeira, a frio; RSLF - extrato aquoso de ramo sadio de lobeira, a frio; e TI - testemunha inoculada. Médias seguidas pela mesma letra não diferem estatisticamente pelo teste de Tukey $(\mathrm{P} \leq 0,05)$. Barras representam o desvio padrão da média.

em cafeeiros e frações desse filtrado demonstraram ação eliciadora de fitoalexina em soja (Guzzo et al., 1987). Tais eliciadores podem ser originados da parede celular do próprio fungo, constituída de moléculas de $\beta$-glucana e quitina, responsáveis por disparar respostas de defesa da planta, aumentando os níveis de compostos fenólicos e as atividades de peroxidases e polifenoloxidases (Guzzo et al., 1987; Maxemiuc-Naccache \& Dietrich, 1985). Entretanto, quando se usam apenas os esporos de ferrugem para induzir resistência em plantas, descartam-se os eliciadores endógenos presentes nos próprios tecidos das folhas de cafeeiro e disponibilizados após a colonização fúngica. Na continuidade desse projeto, serão testados extratos procedentes de tecidos de cafeeiros resistentes à ferrugem (extratos aquosos e também metanólicos dos mesmos).

Experimento 2. Estudo da proteção induzida em cacaueiro contra a vassoura-de-bruxa, por extratos provenientes de basidiomas de Crinipellis perniciosa e de vassouras-de-lobeira

Pelos dados obtidos aos 60 dias após a inoculação (Figura 1B), os extratos de lobeira proporcionaram proteção semelhante ao tratamento padrão com o ASM. Entretanto, 
o extrato aquoso de ramo sadio de lobeira a frio não diferiu estatisticamente da testemunha. Além disso, os tratamentos com extratos de basidiomas e o referido extrato a frio, tiveram desempenho intermediário entre a testemunha inoculada e os demais tratamentos. Cavalcanti et al. (2006a), verificaram que a eficácia de extratos de vassouras-delobeira foi estatisticamente igual a do ASM, para a proteção do tomateiro contra Xanthomonas vesicatoria.

Em ensaio realizado in vitro (dados não mostrados) constatou-se que o VLA e o ASM, não apresentaram efeitos tóxicos diretos sobre o crescimento de C. perniciosa, o que é esperado para um indutor de resistência, pois esses não atuam diretamente sobre o patógeno (Kúc, 2001). Convém ressaltar que os tratamentos com VLA, nas diluições testadas, potencializaram o crescimento micelial do fungo. Possivelmente, o VLA possui em sua composição, substâncias que poderiam ativar o crescimento do fungo, como açucares simples ou complexos, por exemplo. Por outro lado, essas e outras substâncias como proteínas e lipídios, podem estar servindo como eliciadores de respostas de defesa em plantas.

$\mathrm{Na}$ concepção do extrato de ramos infectados de lobeira, foi hipotetizada a obtenção de eliciadores, tanto exógenos (provenientes do patógeno) como endógenos (provenientes da planta). Nesse provável 'coquetel' de eliciadores devem estar presentes numerosas moléculas solúveis advindas do próprio patógeno e da parede celular do hospedeiro. Após o ataque fúngico, muitos polímeros da parede do hospedeiro são quebrados e os oligossacarídeos liberados podem agir como eliciadores endógenos, ativando o sistema de defesa da planta (Hammond-Kosack \& Jones, 2000).

Após estes resultados e hipóteses, passou-se a estudar os mecanismos envolvidos na proteção de mudas de cacau, pelo extrato aquoso e fervido de vassouras provenientes de lobeira, extrato denominado VLA nos experimentos seguintes.

\section{Experimento 3. Caracterização dos mecanismos bioquímicos envolvidos na resposta de defesa de mudas de cacaueiros tratadas com ASM e VLA}

\section{Determinação da atividade de peroxidase}

As atividades de peroxidase de guaiacol em mudas de cacaueiros aumentaram nos tratamentos com ASM e VLA, em todo o intervalo estudado (de 4 a 18 dias após a aplicação dos produtos), comparada ao tratamento controle pulverizado com água somente (Figura 2A).

Eletroforese em gel em condições nativas confirmou o aumento das atividades de peroxidases das amostras avaliadas no ensaio colorimétrico. Tanto o VLA quanto o ASM, aumentaram a expressão de uma isoforma ativa de peroxidase revelada por diaminobenzidina, a partir de quatro dias após as pulverizações com os respectivos indutores de resistência; esses aumentos persistiram até 13 dias após as pulverizações (data da última análise, no caso), a julgar pela intensidade das bandas observadas no gel (Figura 2B).

A atividade de peroxidases frequentemente aumenta em resposta aos estresses. Peroxidases específicas (como as de guaiacol), catalizam a oxidação de álcoois fenólicos à lignina,

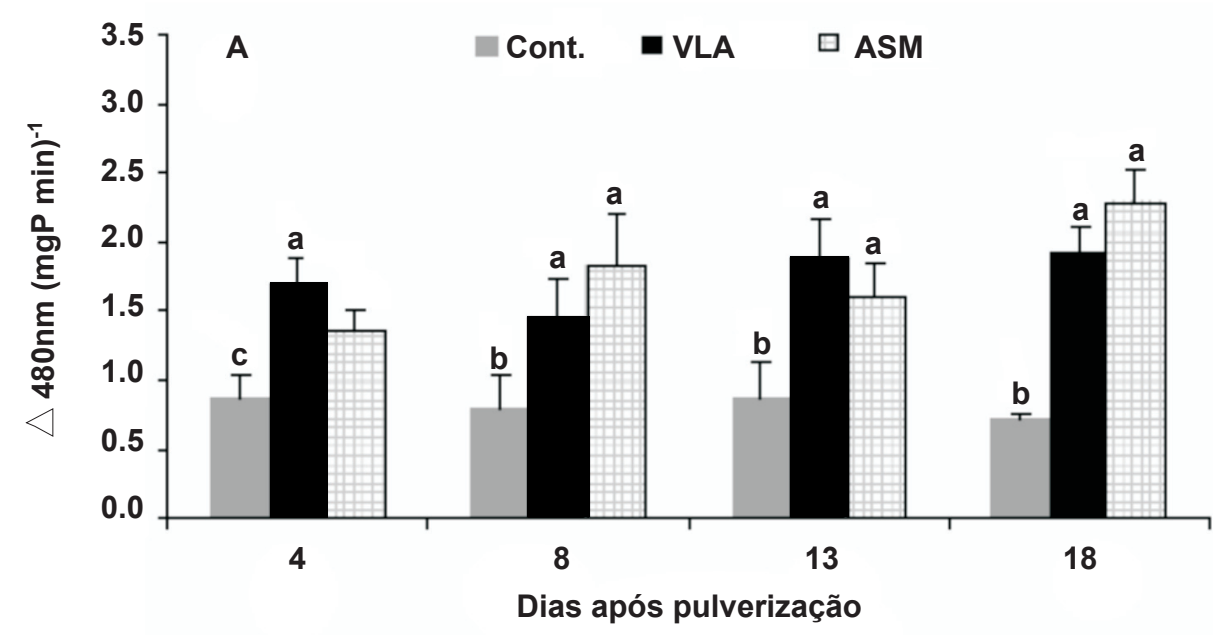

B

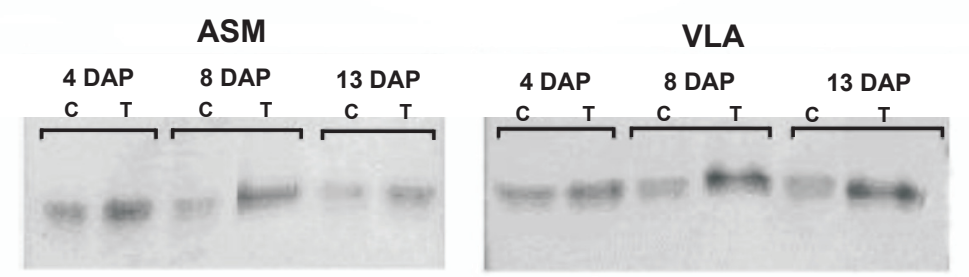

FIG. 2 - A. Atividade peroxidase de guaiacol nos tempos de 4, 8, 13 e 18 dias após pulverização; B. gel de eletroforese em condições nativas revelando uma isoforma de peroxidase nos tempos de 4, 8 e 13 dias após a pulverização (DAP), em brotações novas de mudas de cacaueiros pulverizadas com ASM (acibenzolarS-metil) ou VLA (extrato aquoso de vassoura-de-lobeira, fervido). $\mathrm{C}=$ controle e $\mathrm{T}=$ tratada. Médias com mesma letra em cada dia de coleta não diferem entre si pelo teste de Tukey $(\mathrm{P} \leq 0,05)$. Barras representam os desvios padrões das médias. 
ao mesmo tempo em que reduzem peróxido de hidrogênio à água. A lignificação da parede celular é caracterizada como uma das reações desencadeadas pelo sistema de defesa da planta para tentar impedir a penetração ou restringir a colonização de tecidos vegetais por patógenos (Resende et al., 2002a).

\section{Determinação do conteúdo de lignina}

Quando se quantificou o conteúdo de lignina em tecidos jovens de cacau, observou-se que tratamentos com VLA ou ASM induziram maior acúmulo deste polímero fenólico aos 18 dias após a pulverização, comparados com o respectivo controle pulverizado com água (Figura 3). A lignificação precoce dos tecidos jovens é, portanto, um dos mecanismos de defesa ativados em cacaueiro contra C. perniciosa, fungo que coloniza somente tecidos tenros. Resende et al. (2002b) verificaram que mudas de cacaueiros tratadas com ASM permaneceram com mecanismos de defesa ativados, até 30 dias após a aplicação do referido produto. Estudos desse tipo podem fornecer subsídios para se inferir sobre periodicidade de aplicação de indutores de resistência em plantas.

Qualquer produto ou extrato para ser considerado um bom indutor de resistência também deve possuir ação de amplo espectro, combatendo não somente doenças fúngicas, mas também bacterianas e outras relevantes para a agricultura. No caso do algodoeiro, o tratamento com VLA, teve desempenho estatisticamente similar ao proporcionado pelo ASM, o qual conferiu proteção de cerca de 62,3\%, contra a mancha angular do algodoeiro, causada por $X$. axonopodis pv. malvacearum (Smith 1901) Vauterin, Hoste, Kersters \& Swings 1995. Com relação à mancha bacteriana do tomateiro, causada por $X$. vesicatoria (um modelo mais simples e mais rápido de ser estudado do

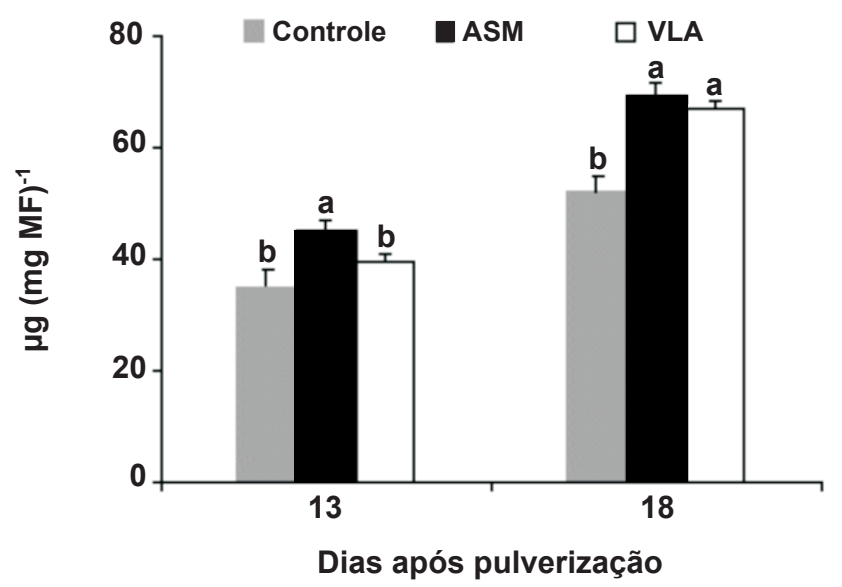

FIG. 3 - Conteúdo de lignina ácido-solúvel total ( $\mu \mathrm{g}$ por mg de matéria fresca) em mudas de cacaueiros 13 e 18 dias após a pulverização dos tratamentos. Tratamentos: ASM (acibenzolarS-metil), VLA (extrato aquoso de vassoura-de-lobeira, fervido) e Controle (pulverizado apenas com água). Médias com mesma letra em cada dia de coleta não diferem entre si pelo teste de Tukey $(\mathrm{P} \leq 0,05)$. Barras representam os desvios padrões das médias. que a vassoura-de-bruxa no cacaueiro), exaustivos ensaios foram conduzidos com o VLA. Em tomate, a expressão de peroxidases foi aumentada a partir do terceiro dia após as pulverizações, tanto com VLA, quanto com o indutor de resistência padrão ASM, sendo que cinco isoformas de peroxidases foram detectadas, nove dias após as pulverizações (DAP), com ambos os indutores de resistência. No último passo dessa pesquisa utilizando o tomateiro, como modelo para estudar o VLA, chegou-se ao isolamento de uma fração protéica procedente do VLA, com forte capacidade de eliciação de peroxidases e outras respostas de defesa (Cavalcanti et al., 2007).

\section{Determinação das atividades de quitinase e $\beta$-1,3- glucanase \\ Nota-se na Figura 4A que, quando as mudas} de cacau foram tratadas com ASM ou VLA, houve um incremento maior nas atividades de quitinase aos oito dias; a partir de então, houve decréscimos não muito acentuados nas atividades da mesma, apresentando ainda atividades superiores à do tratamento controle, aos 18 dias após a pulverização. Já as atividades de $\beta$-1,3glucanase nos tratamentos com ASM e VLA se elevaram até os 13 dias após a aplicação e começaram a declinar a partir de então, chegando a níveis estatisticamente iguais ao da testemunha, aos 18 dias (Figura 4B). Essas maiores atividades de quitinase e de $\beta$-1,3-glucanase conferidas por VLA, embora tenham declinado com o tempo, foram induzidas precocemente, podendo estar relacionadas com maior chance de sucesso no combate a C. perniciosa, através da degradação de componentes da parede celular do mesmo. Quitinases e $\beta$-1,3-glucanase são enzimas que hidrolisam respectivamente quitina e $\beta$-1,3-glucana, principais polímeros componentes da parede celular de fungos, tendo, portanto, ação tóxica direta sobre esses patógenos. São consideradas PRP's e são potentes marcadores de indução de resistência em plantas (Van Loon \& Van Strien, 1999).

A resistência induzida é expressa tanto de forma local como sistêmica em resposta a patógenos. A resistência expressa sistemicamente (SAR) está associada ao aumento de atividade de PRP's e é mediada por um processo dependente do ácido salicílico. Outros processos de defesa podem ser incluídos, como explosão oxidativa, acúmulo de fitoalexinas, lignificação, deposição de calose e conseqüente enrijecimento de parede (Durrant \& Dong, 2004). Embora as PRP's estejam implicadas na defesa de plantas, não têm necessariamente ação antimicrobiana. Na verdade, as PRP's são identificadas por seu simples acúmulo em plantas submetidas a uma situação de patogênese (Van Loon, 1997). Entretanto, estudos recentes têm mostrado que a super expressão de genes de quitinases e glucanases em plantas, tem aumentado a resistência dessas plantas a patógenos (Van Loon et al., 2006), inclusive do cacaueiro a Colletotrichum gloeosporioides (Penz.) Penz. \& Sacc. (Maximova et al., 2006). 

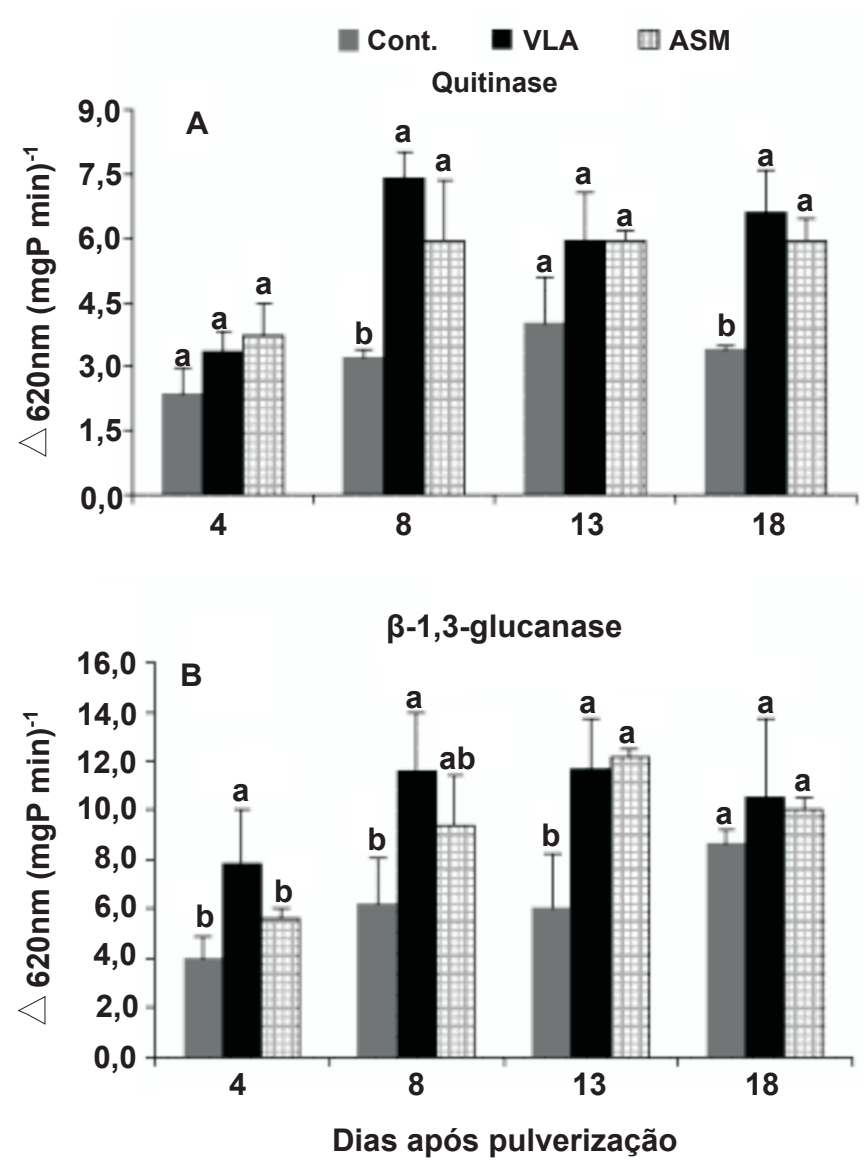

FIG. 4 - Atividade de quitinase (A) e $\beta$-1,3-glucanase (B) em brotações novas de mudas de cacaueiros, após os tratamentos: ASM (acibenzolar-S-metil), VLA (extrato aquoso de vassoura-delobeira, fervido) e Cont. (controle). Médias com mesma letra em cada dia de coleta e para cada enzima não diferem entre si pelo teste de Tukey $(\mathrm{P} \leq 0,05)$. Barras representam os desvios padrões das médias.

Vários trabalhos têm demonstrado que plantas reconhecem eliciadores derivados da superfície celular, os quais induzem respostas de defesa tanto em plantas hospedeiras como em não hospedeiras. Estes incluem peptídeos, carboidratos, glicoproteínas e lipídios (Nürnberger \& Brunner, 2002). Além disso, PR-proteínas e poligalacturonases de patógenos podem hidrolisar, respectivamente, substratos da parede celular do patógeno ou hospedeiro, causando eliciação indireta pela liberação de produtos eliciadores não-específicos, no ambiente apoplástico (Van Loon, 1997). Foi demonstrado que extratos elaborados a partir de ramos de lobeira infectados por $C$. perniciosa contêm vários eliciadores (Cavalcanti et al., 2007), os quais foram capazes de induzir respostas de defesa em mudas de cacau, contra o mesmo fungo.

Existe uma dificuldade na padronização do extrato de vassoura-de-lobeira, pois naturalmente ocorrem vassouras com maior ou menor colonização do fungo, variando assim a quantidade do eliciador de origem fúngica. Uma maneira de contornar esse problema seria a quantificação do ergosterol nessas vassouras, pois o ergosterol é um lipídio específico de fungos (Gessner \& Smitt, 1996). Após essa quantificação, o extrato poderá ser padronizado de acordo com a concentração do ergosterol, que será uma etapa posterior do presente estudo.

\section{REFERÊNCIAS BIBLIOGRÁFICAS}

ATHAYDE SOBRINHO, C., FERREIRA, P.T.O. \& CAVALCANTI, L.S.C. Indutores abióticos. In: Cavalcanti, L.S., Di Piero, R., Cia, P., Pascholati, S.F., Resende, M.L.V. \& Romeiro, R.S. (Eds.) Indução de resistência em plantas a patógenos e insetos. Piracicaba SP. FEALQ. 2005. pp. 51-80.

BASTOS, C.N. Efeito do óleo de Piper aduncum sobre Crinipellis perniciosa e outros fungos fitopatógenos. Fitopatologia Brasileira 22:441-443. 1997.

BRADFORD, M.M. A rapid and sensitive method for the quantification of microgram quantities of protein utilizing the principle of protein-dye binding. Analytical Biochemistry 72:248254. 1976.

CAVALCANTI, F.R., RESENDE, M.L.V., CARVALHO, C.P., SILVEIRA, J.A. \& OLIVEIRA, J.T. Induced defence responses and protective effects on tomato against Xanthomonas vesicatoria by an aqueous extract from Solanum lycocarpum infected with Crinipellis perniciosa. Biological Control 39:408-417. 2006.

CAVALCANTI, F.R., RESENDE, M.L.V., OLIVEIRA, J.T., SILVEIRA, J.A. \& CARVALHO, C.P. An aqueous suspension of Crinipellis perniciosa mycelium activates tomato defence response against Xanthomonas vesicatoria. Crop Protection 26:729-738. 2007.

COSTA, J.C.B., BEZERRA, J.L., VELOSO, J.L.M., NIELLA, G.R. \& BASTOS, C.N. Controle biológico da vassoura-de-bruxa do cacaueiro. In: Verson, M., Paula JR., T.J. \& Pallini, A. (Eds.) Tecnologias alternativas para o controle de pragas e doenças. Viçosa MG. EPAMIG. 2006. pp. 25-47.

DURRANT, W.E. \& DONG, X. Systemic acquired resistance. Annual Review of Phytopathology 42:185- 209. 2004.

FRIAS, G.A., PURDY, L.H. \& SCHMIDT, R.A. An inoculation method for evaluate resistance of cocoa to Crinipellis perniciosa. Plant Disease 79:787-791. 1995.

GESSNER, M.O. \& SCHIMITT, A.L. Use of solid-phase extraction to determine ergosterol concentrations in plant tissue colonized by fungi. Applied Environmental Microbiology 62:415-419. 1996.

GUZZO, S.D., MARTINS, E.M.F. \& MORAES, W.B.C. Induced protection of coffee plants to Hemileia vastatrix. I. Partial purification of the extracellular inducer from heat-killed urediniospores of the pathogen. Fitopatologia Brasileira 12:377-385. 1987.

HAMMOND-KOSACK, K.E. \& JONES, J.D.G. Responses to plant pathogens. In: Buchanan, B.B., Gruissem, W. \& Jones, R.L. (Eds.) Biochemistry and Molecular Biology of Plants. Rockville MD. ASPP. 2000. pp. 1102-1156.

HOAGLAND, R. \& ARNON, I. The water culture method for growing plants without soil. Circular of the California Agricultural Experiment Station 347:1-32. 1950. 
KÚC, J. Concepts and direction of induced systemic resistance in plants and its application. European Journal of Plant Pathology 107:7-12. 2001.

LAEMMLI, U.K. Cleavage of structural proteins during the assembly of the head bacteriophage T4. Nature 227:680-685. 1970 .

LUZ, E.D.M.N., BEZERRA, J.L., RESENDE, M.L.V. \& OLIVEIRA, M.L. Doenças do cacaueiro. In: Ribeiro do Vale, F.X. \& Zambolim, L. (Eds.) Controle de doenças de plantas. Brasília DF. Ministério da Agricultura e do Abastecimento. 1997. pp. 611-656.

LYON, G.D. \& NEWTON, A.C. Do resistance elicitors offer new opportunities in integrated disease control strategies? Plant Pathology 46:636-641. 1997.

MAXEMIUC-NACCACHE, V. \& DIETRICH, S.M.C. Changes in phenols and oxidative enzymes in resistant and susceptible Coffea arabica inoculated with Hemileia vastatrix (coffee rust). Revista Brasileira de Botânica 8:185-190. 1985.

MAXIMOVA, S.N., MARELLI, J.P., YOUNG, A., PISHAK, S., VERICA, J.A. \& GUILTNAN, M. Over-expression of a cacao class I chitinase gene in Theobroma cacao L. enhances resistance against the pathogen Colletotrichum gloeosporioides. Planta 224:740-749. 2006.

MONTIES, B. Lignins. In: Dey, P.M. \& Harborne, J.B. (Eds.) Methods in plant biochemistry. New York NY. Academic Press. 1989. pp. 113-158.

MORAES, M.G. Mecanismos da resistência sistêmica adquirida em plantas. Revisão Anual de Patologia de Plantas 6:261-284. 1998.

NOJOSA, G.B.A., RESENDE, M.L.V. \& RESENDE, A.V. Uso de fosfitos e silicatos na indução de resistência. In: Cavalcanti, L.S., Di Piero, R., Cia, P., Pascholati, S.F., Resende, M.L.V. \& Romeiro, R.S. (Eds.) Indução de resistência em plantas a patógenos e insetos. Piracicaba SP. FEALQ. 2005. pp. 139-153.

NÜRNBERGER, T. \& BRUNNER, F. Innate immunity in plants and animals: emerging parallels between the recognition of general elicitors and pathogen-associated molecules. Current Opinion in Plant Biology 5:1-7. 2002.

QUINABRA. QUÍMICA NATURAL BRASILEIRA Ltda. Online: http://www.quinabra.com.br/boletinstec/boletim_digital_ecolife. pdf. 2006.

RESENDE, M.L.V., ARAUJO, D.V., COSTA, J.C.B., DEUNER,
C.C., FERREIRA, J.B., MUNIZ, M. F.S., REIS, S.N., SANTOS, F.S., CAVALCANTI, L.S. \& NOJOSA, G.B.A. Produtos comerciais à base de bioindutores de resistência em plantas. Revisão Anual de Patologia de Plantas 14:361-380. 2006.

RESENDE, M.L.V., BARRETI, P.B. \& DIAS, W.P. Percepção, transdução e tradução de sinais para respostas de defesa contra patógenos em plantas. In: I Simpósio de biologia molecular da resistência de plantas a patógenos: aplicações no manejo integrado de fitodoenças. Lavras MG. 2002a. pp. 9-35.

RESENDE, M.L.V., NOJOSA, G.B.A., AGUILAR, M.A.G., SILVA, L.H.C.P., NIELLA, G.R., CARVALHO, G.A., GIOVANINI, G.R. \& CASTRO, R.M. Perspectivas da indução de resistência em cacaueiro contra Crinipellis perniciosa através do benzoatiazole (BTH). Fitopatologia Brasileira 25:149-156. 2000.

RESENDE, M.L.V., NOJOSA, G.B.A., CAVALCANTI, L.S., AGUILAR, M.A.G., SILVA, L.H.C.P., PEREZ, J.O., ANDRADE, G.C.G., CARVALHO, G.A. \& CASTRO, R.M. Induction of resistance in cocoa against Crinipellis perniciosa and Verticillium dahliae by acibenzolar-S-methyl (ASM). Plant Pathology 51:621628. 2002b.

STADNIK, M.J. Induction of resistance in wheat by a benzothiadiazole derivative against the powdery mildew (Blumeria graminis f. sp. tritici): practical aspects and mechanisms of action. Ph.D. Thesis. Universität Hohenheim. Stuttgart. 1999.

VAN LOON, L.C. Induced resistance in plants and the role of pathogenesis-related proteins. European Journal of Plant Pathology 103:753-765. 1997.

VAN LOON, L.C., BAKKER, P.AH.M. \& PIETERSE, C.M.J. Systemic resistance induced by rhizosphere bacteria. Annual Review Phytopathology. 36:453-483. 1998.

VAN LOON, L.C. \& VAN STRIEN, E.A. The families of patogenesis-related proteins, their activities and comparative analysis of PR-1 type proteins. Physiological and Molecular Plant Pathology 55:85-97. 1999.

VAN LOON, L.C., REP, M. \& PIETERSE, C.M.J. Significance of inducible defense-related proteins in infected plants. Annual Review of Phytopathology 44:135-62. 2006.

VIDHYASEKARAN, P. Lignin and disease resistance. In: Vidhyasekaran, P. (Ed.) Physiology of disease resistance in plants. Boca Ratón FL. CRC Press Inc. 1988. pp. 121-135. 